\title{
NOTAS CRÍTICAS SOBRE EL APRENDIZAJE ESTÉTICO
}

\author{
Pablo García Andreva
}

Universidad de Salamanca

\begin{abstract}
RESUMEN. El presente trabajo es una reflexión en torno a la estética como uno de los principales factores que vertebran los patrones de la conciencia social.

Un acercamiento a las influencias de la plástica, -referente de la actividad creadora que coordina los aspectos emocionales e intelectuales en la educación del niño-, nos mostrará la importancia que conlleva el hecho de mediar en el aprendizaje de un equilibrado juicio estético.

ABSTRACT. The present essay is a reflection concerning aesthetics as one of the main factors that organize the patterns of social conscience.

An approach to the influence of plastic arts (which are the reference of creative activity that coordinates emotional and intellectual aspects of child's education) will show us the importance embedded in the fact of intervening in the learning of a balanced and aesthetic judgement.
\end{abstract}

\section{Introducción}

Cuando dejamos de ser niños, ya estamos muertos. BRANCUSI

(Escultor, 1876-1957).

Todas las sociedades se hallan en la certeza de admitir sus propios conocimientos como balanza en la baremación de valores culturales propios frente a los extranjeros. Asumiendo, así, la teoría orteguiana de ver lo extranjero como bárbaro -por lo tanto, distante-. Esta afirmación no produciría mayor trascendencia reflexiva si no fuera por la paradoja a la que se la somete en el tiempo presente. Dicho de forma directa: a la cultura occidental se le antoja como bárbara -distante- su propia cultura occidental. Y menciono el verbo "antojar" porque comprendo como prejuicio -por tanto, sin bastante examen- y no como juicio, los atropellos culturales que se ciernen, en concreto, sobre los planteamientos educativos de la plástica. En realidad, es un problema de base ya que, por motivos que no procede razonar aquí, la estética del Arte Contemporáneo no solamente no es, por lo general, aceptada socialmente sino que más bien, en un tanto por ciento excesivamente significativo, es rechazada y menospreciada. Sin embargo: "Las posiciones de la estética tradicional -sistemática y especulativa- son 
insostenibles a medida que se hace tangible la muerte del arte en sus formas tradicionales, tal como comprobamos históricamente entre 1900 y 1930."1

Las sociedades siempre han necesitado una definición abstracta de lo establecido como arquetipo del valor estético para conducir y dirimir cualquier clase de juicio plástico relativo al gusto. Jamás dicha conciencia colectiva había configurado un concepto artístico tan distante de los valores plásticos coetáneos como en este siglo XX. $\mathrm{Y}$ ello es fundamentalmente debido a un turbio problema de aprendizaje. Sintetizando se podría decir que, en relación con cualquier campo de conocimiento, lo que no se comprende -pero sí se supone que se debería comprender- es repudiado; lo repudiado no es asumido como valor, por lo tanto no es trascendente; y si no es trascendente, no necesita de reflexión, lo cual dificulta gravemente la labor de comprensión. En consecuencia, en lo que respecta al valor estético en esta sociedad occidental supone una ingenua y cómoda apuesta por unos planteamientos plásticos ya caducos, que se presumen comprender, y que de ninguna manera pueden ni por asomo ser reflejo -cosa que por otra parte siempre le ha sido intrínseco al Arte- de la estructura de la problemática presente, colmada de fugaces acontecimientos plurales y constantes. "Si comprendemos mejor la existencia de una relación incesante, y variable según marcos sociales, entre el conjunto de fuerzas que están comprometidas en la trama de la vida colectiva y la creatividad, estaremos en condiciones de captar mejor la realidad existencial de la obra de arte." ${ }^{2}$

Platón, que nunca tuvo una idea global del Arte, se percató de la extremada importancia del mismo reconociendo que actúa directamente sobre el sentimiento y el intelecto, por lo tanto como un ente capaz de propagar conocimiento y valores morales. Sin embargo, encontramos cierto recelo en numerosas citas de sus famosos escritos en las que defiende someter al Arte a una vigilancia absolutamente dictatorial en pro de un supuesto bien comunitario. En Las Leyes (Libro II) afirma: "Y para que, en efecto, el alma del niño no se acostumbre a gozar o a apesadumbrarse en contra de la ley, ... el buen legislador persuadirá al poeta, o le obligará, si no le persuade a expresar, como debe, con bellas y nobles palabras, en sus ritmos, imágenes y melodías, la música de los hombres serenos, valientes y, en todo sentido, buenos. ${ }^{\prime \prime}$, o en La República (Libro III): "Por consiguiente, no sólo tenemos que vigilar a los poetas y obligarles o a representar en sus obras modelos del buen carácter, o a no divulgarlas entre nosotros, sino que también hay que ejercer inspección sobre los demás artistas e impedirles que copien la maldad, intemperancia, vileza o fealdad." ${ }^{\prime 4}$

La historia ha demostrado que una dura represión en la evolución natural del Arte produce movimientos o periodos artísticos vacuos, asincrónicos, maniqueos, intrascendentes y subversivos. Ejemplos constatables encontramos tanto en el Realismo

1. Marchán Fiz, S. La estética de la cultura moderna. Alianza Forma, Madrid, 1987, pág. 232.

2. Duvignaud, J. Sociología del arte. Ed. Península, Barcelona, 1988, pág. 143.

3. Platon, Las Leyes. (Libro II), Centro de estudios constitucionales, Tomo I, traducción de José Manuel Pabón, Madrid, 1983, pág. 35.

4. Platon, La República. (LibrollI), Centro de estudios constitucionales, Tomo II, traducción de José Manuel Pabón, Madrid, 1981, pág. 31. 
Socialista ruso como en la época imperial de ocupación alemana con el denominado Arte Nazi; el partido nacional-socialista lo llamaba Arte No Degenerado.

Ciertamente, atentar en contra de la libertad creadora es destruir por completo la esencia misma de la creación. Pero aunque los postulados platónicos relativos al Arte se nos muestran, hoy en día, como afirmaciones educativas pseudototalitaristas -por tanto execrables- sin embargo, de manera inocente, inconsciente, dogmática, convencida y social, la inmensa mayoría de familias y numerosos colegios ofrecen una enseñanza condicionada por principios estético-plásticos obsoletos.

Cabe preguntarse la importancia relativa que concierne a una correcta educación plástica, sobre todo en los primeros 10-12 años de vida del niño. Y es que no estamos hablando de una preparación técnica que favorezca las cualidades artísticas de un individuo para la hábil producción de sus hobbies ulteriores de adultez. El interés es ostensiblemente más grave pues afecta al empleo constructivo de las emociones, a la coordinación psicomotora, a la potenciación de la capacidad de abstracción, al desarrollo intelectual, al concepto referencial de autoidentificación, al medio de expresión, a la estimulación de la percepción, a la conciencia social, a la sensibilidad estética, al uso de la actividad creadora, etc.; aspectos, todos ellos, absolutamente relevantes para el buen desarrollo evolutivo del ser humano. Mi intención, pues, en estas líneas no es la de condenar, ni destruir, ni sustituir sistemas de enseñanza sino que pretendo apoyar una postura de aperturismo educativo en la labor del docente acorde con un paralelismo estético actual y respetando los procesos lógicos de aprendizaje infantil, con el fin de no dañar las capacidades potenciales del individuo y, al tiempo, evitar criar seres alienados de su propia cultura autóctona. "Pese a su pérdida de sensibilidad estético-artística, el ser humano actual es portador de un proyecto de educación estética que lo acompaña a lo largo de toda su vida." ${ }^{5}$.

\title{
2. El fantasma del aprendizaje estético-plástico contemporáneo
}

\author{
En verdad, lo sentimos cuando el \\ niño pierde su inocencia, y un despertar \\ descontento con el cómo estropea su \\ gusto por el dibujo. \\ E. H. GOMBRICH
}

Vasari, primer historiador y testigo del arte del Renacimiento, relató una apuesta que Miguel Ángel realizó en su juventud con sus amigos pintores, en la cual se competía por la destreza de copiar un garabato infantil hecho en una pared. Si Miguel Angel no fuese un artista fuera de serie, el dibujo "anónimo" no tendría más valor que el de un curioso objeto histórico. Pero el hecho es que sí que tuvo que ser un auténtico reto estético pues suponía, no sólo un cambio de actitud frente al dibujo sino todo un cambio radical de concepción plástica impuesto por un modelo ingenuamente complejo. "Una proeza difícil para un hombre tan impregnado de diseño", escribió Vasari. Aunque, analizándolo artísticamente, que el dibujo fuese una copia de algo

5. Gennari, M. La educación estética. Instrumentos Paidós, Barcelona, 1994, pág. contraportada.

6. Gombrich, E. H. Temas de nuestro tiempo. Debate, Madrid, 1997, pág. 97. 
realizado con otra intencionalidad, anula cualquier posibilidad de investigación de un lenguaje plástico alternativo por el único fin de exhibir llanamente unas habilidades manuales. Es en este punto donde radica lo que considero núcleo principal de la paradoja estético-plástica actual, ya que, bien sea Miguel Ángel, en este caso, como tantos otros artístas que gozan comunmente del respeto del público, son normalmente admirados no por unas carácterísticas absolutamente estéticas sino precisamente por este dibujo, o sea por su eficacia técnica -suele denominarse "tener buena mano"- en las elaboraciones artísticas. ¡Esto no lo puedo hacer yo! Es como si realmente subyaciese en la mente del espectador una absurda idea de competición, de exhibición, que atacara sus posibilidades plásticas. Me explico: a lo largo de la Historia del Arte, la mímesis ha ocupado un lugar realmente interesante y fundamental (Grecia, Renacimiento, etc.) como planteamiento estético pero no ha sido ni la única ni la más correcta opción artística, pues no simplemente no hay opciones plásticas mejores unas que otras sino que a cada tiempo le corresponde la suya como la exclusivamente válida. Lo cual, por supuesto, no quiere decir que no se deban ensalzar actitudes estéticas pasadas y disfrutar de ellas. Sinceramente, he de reconocer que admiro de la mímesis muy diferentes factores pero encuentro que la complejidad de representación técnica -"buena mano"-, aun siendo extremadamente atractivo su interés, no es ni con mucho la mejor de sus cualidades. Pues bien, los posos de estas loables dificultades técnicas son los que se han asentado y convertido en las máximas estéticas sociales, atribuyéndole, normalmente, un valor al Arte de pura exigencia de destreza manual para la elaboración de técnicas miméticas.

En este siglo, donde el "parecerse a" prima profundamente sobre el "ser" es completamente lógico que la conciencia común se mostrase en contra de los valores estéticos del Arte Contemporáneo -veracidad y provocación-, y en lo educativo se manifestara en forma de la anulación de los mismos e inculcación de unos clásicos valores miméticos. Esto se traduce en que, a largo plazo, el individuo no encuentra el sentido al arte de su tiempo y, lo que es mucho peor, a corto plazo sus padres o educadores ataquen el proceso lógico de evolución plástica infantil produciendo graves daños en sus modos de actuación creativa, lo que puede repercutir muy seriamente en su desarrollo evolutivo. Consiguiendo en algunos casos que los niños puedan adquirir desde diferentes grados de trastornos de personalidad (inseguridad, timidez, aislamiento, etc.) hasta trastornos en el desarrollo intelectual (deficiencias lingüísticas, desordenes conceptuales y estructurales, etc.) que literalmente pueden conducir a que el niño sea más "tonto", o sea, a mermar sus capacidades potenciales. "La organización de nuestras aptitudes intelectuales, el refinamiento de nuestra habilidad perceptiva y la íntima relación con nuestra capacidad emocional pueden considerarse como desarrollo estético." ${ }^{\prime 7}$.

Quiero dejar bien claro que me estoy refiriendo principalmente a cuando el niño se halla en las etapas iniciales del aprendizaje pues, obviamente, los procesos lógicos del desarrollo creador se van enriqueciendo paulatinamente y pueden participar, si el niño siente que lo necesita y desea, de unas propuestas miméticas en etapas conceptuales posteriores.

7. Lowenfeld, V. Desarrollo de la capacidad creadora. Kapelusz, Buenos Aires, 1972, pág. 366. 


\section{Historia e historias}

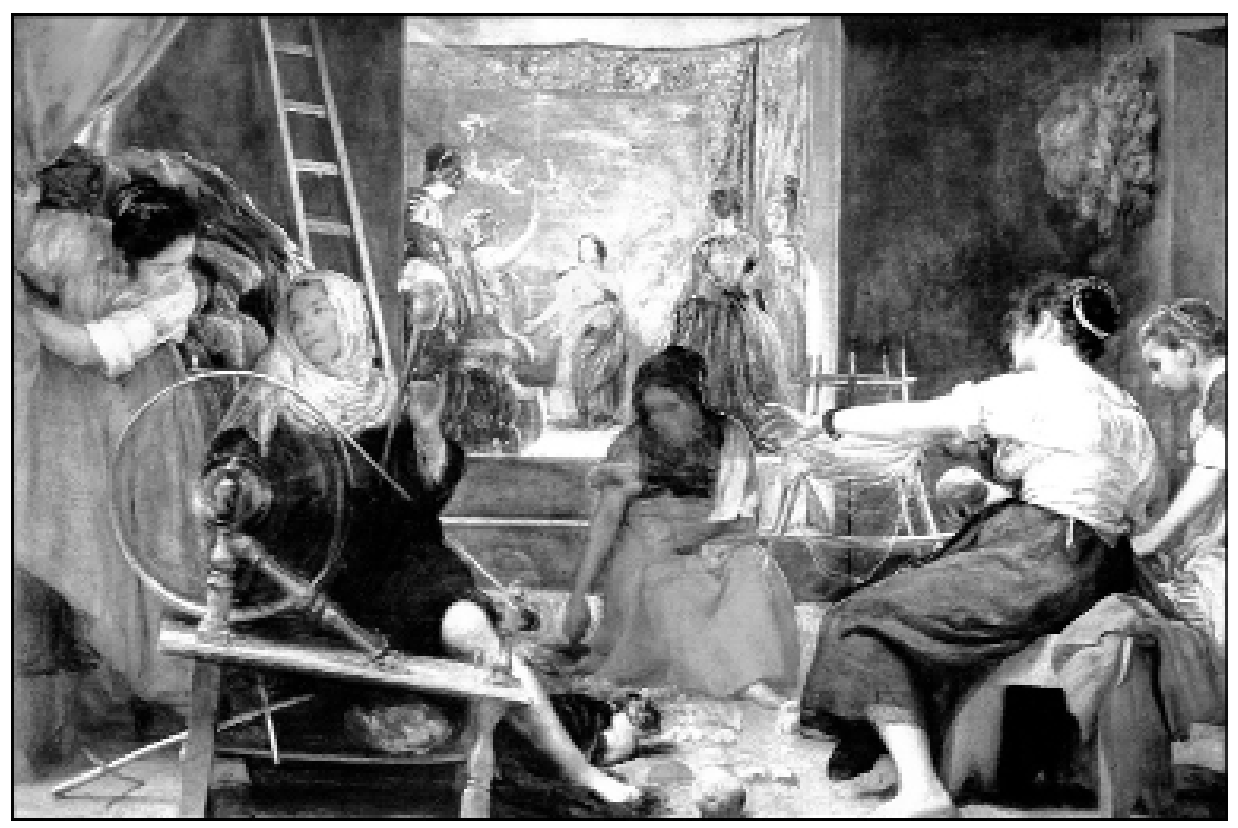

"Las hilanderas" de Velázquez

Al contemplar el famoso y magnífico cuadro de Las Hilanderas (1644-1648) del gran pintor Diego Velázquez, uno tiende a interpretarlo como una novedosa representación pictórica de las manufacturaciones artesanales de la época en la que se nos muestran las dos notables y diferentes clases sociales por las que se desenvolvía el artista. Pero el hecho es que esto solo conformaría una reflexión epidérmica en la lectura de la obra pues, además de ello, subyace una alegoría del Sexto Libro de Las metamorfosis de Ovidio en la que la diosa Palas Atenea se bate en duelo con Aracne a la que castiga transformándola en araña. Lo que trato de exponer es la frecuencia con la que somos vapuleados por los condicionantes perceptuales y cognitivos en pro de una conformación de sentido; acto absolutamente natural. Y es que, realmente, el sentido es esencial en nuestras construcciones ideológicas. El problema radica cuando dicho sentido no goza de una obviedad pura.

Normalmente, tendemos a una concepción parcial de la Historia basada más en acontecimientos, revoluciones, descubrimientos -en definitiva, cambios- que en analizar la coherencia global, atemporal e interracial de lo estable en el ser humano. En cuestiones estéticas, esta coherencia histórica actúa no sólo como la coordinadora en las reflexiones que definen un periodo concreto - "la obra creadora constituye un proceso histórico consecutivo donde cada nueva forma se apoya en las precedentes" ${ }^{\prime{ }_{-}}$, sino como algo sustancialmente más importante ya que nos sirve de guía en los intentos de argumentar las actitudes, los valores, en definitiva la esencia misma del ser humano.

8. Vigotsky, L.S. La imaginación y el arte en la infancia. Ed. Akal, Madrid, 1982, pág. 37-38. 
La dificultad, como ya mencionaba antes, en la conformación de un sentido histórico se ve enturbiada, en repetidas ocasiones, por factores de distanciamientos espaciales y temporales. Pero no debemos dejarnos confundir por las primeras impresiones -como en el cuadro de Velazquez- y hagamos un esfuerzo por replantearnos nuestros conocimientos estéticos organizados de forma jerárquica, y delimitados en conpartimentos no interactivos. "La lucha contra una estética unitaria o determinada... da lugar a una variedad y cantidad estéticas que se unen, se separan, entran en conflicto, evolucionan, hacen sitio a otras nuevas que se superponen o bien descalifican a las anteriores. ${ }^{\prime \prime}{ }^{2} \mathrm{O}$ acaso es posible entender el cuadro de Las señoritas de Avignon sin tener en cuenta la filosofía estética del Arte Africano?

Lo cierto es que si meditamos en torno a las conductas que articulan los mecanismos estéticos del Arte a lo largo de toda la historia y en todo lugar, encontramos que en casi todos los periodos y casi todas las culturas -incluyendo la nuestra occidental actual- hay un valor plástico -el mal llamado Arte Primitivo- con unas actitudes formales que comulgan de lo que hoy venimos a denominar Arte Infantil. Permítaseme citar un extenso texto del insigne historiador del arte E. H. Gombrich, que por su rotundidad y claro posicionamiento me es profundamente grato: "Sólo se puede "atrapar" la apariencia de la naturaleza mediante una estrategia indirecta. Pero, paradógicamente, conocer la complejidad de la "trampa" me hace poner en entredicho la definición de los estilos no naturalistas como primitivos. Son la regla y no la excepción, porque el método "normal" de hacer una imagen emplea lo que se llama un esquema conceptual, que encarna lo que se sabe en vez de lo que se ve. Llamar "primitivo" a este método normal es tan engañoso como llamar "caminar" a una forma de locomoción primitiva porque hemos desarrollado el motor de combustión interna."10

En consecuencia, deducimos que la conceptualización estética del Arte Primitivo, o mejor dicho Arte Normal -semejante formalmente al Arte Infantil pero distinto en concepciones técnicas, cognitivas, normativas, pragmáticas, etc.- , posee unos principios plásticos tan sólidos que pertenecen al método racional discursivo con el que el ser humano aprehende la realidad; de otro modo dicho: son los pilares universales

\section{del aprendizaje estético.}

Recordemos un momento desde el Arte Rupestre europeo al Arte Aborigen australiano, desde el Arte Hindú al Arte Oriental, desde el Arte Egipcio y Mesopotámico al Arte Africano y Esquimal, desde el Arte Celta, Vikingo y Medieval al Arte Precolombino y de los Indios Norteamericanos, etc., y tratemos de abstraer sus cualidades plásticas ( formales, espaciales, etc.). Llegamos a la conclusión de atisbar una unicidad que diluye las diferencias técnico-culturales, y al tiempo nace una idea de sistematización lingüística -el Arte es un lenguaje visual- atemporal e internacional, que se constata en las diferentes etapas evolutivas del aprendizaje del Arte en los niños.

Cabría llegar a pensar que el desarrollo del Arte Primitivo o Normal ha tenido su supuesta consecución última y superior en los periodos de representación mimética pero la total trasgresión de dichos valores llevada a cabo por las vanguardias a prin-

9. Viñuales González, J. Criterios de valoración del Arte Actual. Universidad Nacional de Educación a Distancia, Madrid, 1995, pág. 16.

10. Gombrich, E. H. Gombrich esencial. Debate, Madrid, 1997, pág. 323. 
cipios de siglo dejan sin ninguna posibilidad una afirmación semejante. "Adoptando como tal (como medio) el concepto imitativo caeríamos indefectiblemente en lo que podríamos llamar perfección incompleta."11

\section{Un ejemplo: el garabato ontológico}

El expresionismo se lanza a la búsqueda no solo de la tensión estética, sino también existencial. Ángel González García ${ }^{12}$

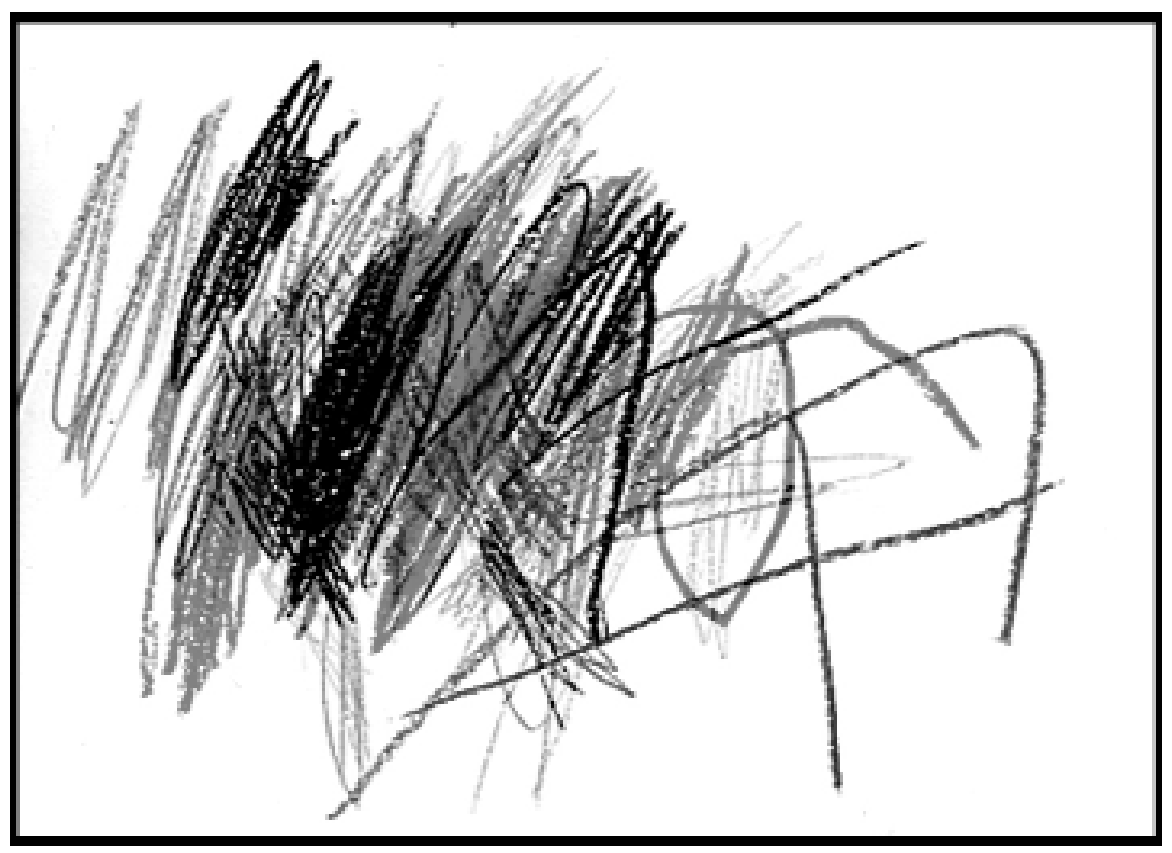

Dibujo realizado por una niña de dos años y ocho meses

La etapa del garabato en los niños es un periodo plástico inicial pero sumamente interesante. Por primera vez, y como hábito, el niño comienza a identificarse emocionalmente con algo que no es él mismo pero que sin embargo sí nace de él. Digámoslo llanamente: el niño comienza a disfrutar del placer de la creación. En su caso es un sentimiento muy primario pero también completamente sincero y libre, y produce una atracción tal que se convierte en una necesidad visual para el estímulo del enriquecimiento intelectual. Se podría añadir que es algo casi biológico pues hasta nuestros predecesores y "primos", los monos, actuán con ciertos paralelismos iniciales. "Los jóvenes chimpancés exploran con igual entusiasmo que nosotros las posibilidades visuales de hacer señales en una hoja en blanco."13 Es obvio que luego los

11. Ferrant, Á. Todo se parece a algo. Visor, Madrid, 1997, pág. 87.

12. González García, Á. Escritos de Arte de Vanguardia 1900/1945. Ed. Turner, Madrid, 1979, pág. 88.

13. Morris, D. El mono desnudo. Plaza y Janés, Barcelona, 1980, pág. 111. 
monos son incapaces de extraer conclusiones como la de recordar las imágenes estéticas con la intención de reproducirlas a voluntad, y por tanto no consiguen relacionar los diferentes elementos que integran los valores formales, quedando exentos de deducciones estéticas. Pero en el ser humano estas reflexiones formales se articulan de manera sistemática. "El Arte es tan natural como el movimiento en los seres humanos $y$, por tanto, tienen aspectos arquetípicos y universales." ${ }^{14}$

Puesto que todo el mundo es más o menos consciente de las subetapas del garabato en el niño (primero es un garabato incontrolado y yuxtapuesto que paulatinamente se va controlando e individualizando hasta el punto de ponerle nombre; momento realmente importante pues cambia de un pensamiento kinestésico a un pensamiento imaginativo) por ello considero que es, de alguna manera, más interesante intentar hacer un rápido repaso histórico valorando al garabato desde un punto de vista menos infantil y más universal.

Si rebuscamos entre la Historia dónde se hallan los comienzos artísticos del hombre nos tendríamos que remontar hasta el Arte Rupestre, y si pretendemos encontrar cúales son las primeras manifestaciones plásticas dentro de este Arte Rupestre, entonces estaremos hablando de lo que los arqueólogos e históriadores denominan macarrones y signos de admiración. Mientras que los macarrones son "signos ondulantes y paralelos trazados con los dedos directamente sobre arcilla blanda"15 que podrían medir hasta seis metros, recorriendo las paredes y techos de las cabernas, los signos de admiración son cortos, de trazo firme y acaban abruptamente. Analizando estas líneas y rayas, al margen de las posibles connotaciones simbólicas o rituales, nos damos cuenta de que son las pruebas de una primera intencionalidad plástica en el ser humano pues actúan en un objeto a través de un medio provocando evidentes cambios formales que configuran un lenguaje visual; o sea, voluntad estética. Y si somos capaces de abstraer tan solo los planteamientos formales de dichas líneas, observaremos que en realidad son la primeras muestras fidedignas de lo que hoy venimos a denominar garabatos. Pero el garabato no siempre se manifiesta de forma tan evidente. Es bien sabido que hay un tipo de garabatos que, si por supuesto, como es lógico, no tratan de representar la realidad, sí que son controlados y premeditados por el niño. En este tipo de garabato controlado están basados o derivados prácticamente todos los símbolos icónicos que representan los elementos alfabéticos de idiomas tan variados como el fenicio, con sus consiguientes evoluciones del hebreo y árabe moderno -"con la llegada del Islam, el espíritu artístico de los árabes se dirigió hacia la decoración abstracta, debido a la general reluctancia de los musulmanes hacia la imaginería." ${ }^{16}$ - o el griego y su derivado latino, etc.

Pero es en el caso de los caracteres pictográficos orientales en donde podemos contemplar las mayores y más directas evidencias del paralelismo entre la caligrafía y el garabato controlado del Arte Infantil. "La presencia del pasado nos liga con nuestros antecesores... y da un sabor de eternidad. ${ }^{117}$ Este modo pictográfico oriental está funda-

14. kellogg, R. Análisis de la expresión plástica preescolar. Cincel, Madrid, 1979, pág. 224.

15. Giedion, S. El presente eterno: Los comienzos del Arte. Alianza Forma, Madrid, 1981, pág. 122.

16. Robinson, A. La historia de la escritura. Ed. Destino, Barcelona, 1996, pág. 174.

17. Beljon, J. J. Gramática del Arte. Celeste Ediciones, Madrid, 1993, pág. 136. 
do sobre una idea poética de las leyes del ritmo y el movimiento, y no sobre medidas de funcionalidad y economía. Mantener el tiempo es repetición, todo lo contrario del ritmo que es constante renovación; es ahí donde se halla la fuerza vital de la caligrafía china. Este "garabato controlado oriental", que debido a la cadencia del ritmo goza de flexibilidad, es fácilmente justificable en nuestra actitud a la hora de plasmar las rúbricas que nos representan en las firmas. Debo añadir, además, que hay en relación con el amplio campo de las firmas como productos portadores de características de garabatos controlados un tipo de rúbricas realmente singular: el Tag. Para reflexionar sobre el Tag nos es absolutamente imprescincible mantener al margen todo tipo de elementales críticas morales, pues los Tags son esas firmas realizadas con sprays y rotuladores anchos que desde hace 20 años bombardean todos los lugares de las ciudades occidentales.

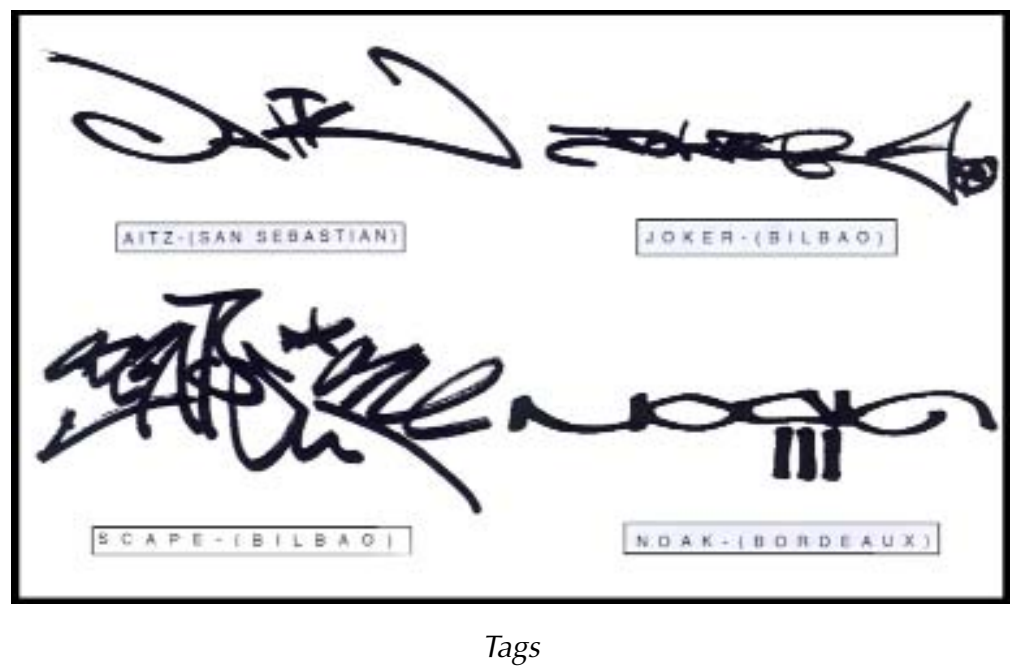

Nos guste o no, en el fondo el Tag es un verdadero fenómeno social que actúa como una manifestación exigente y egocéntrica del individuo en una sociedad despersonalizada; $y$, en lo que nos concierne, es un modo impositivo y establecido del mantenimiento social y actual del potencial estético del garabato como signo poseedor de valores plásticos -aunque tenga repercusiones destructivas-, los cuales en este caso derivan en aunar simbióticamente verbalidad e iconicismo. "La ambigüedad del verbo graphein (raíz etimológica de graffiti) no distinguía entre la práctica propiamente alfabética y la actividad puramente pictórica. ${ }^{\prime 18}$ Los trazos de estas firmas callejeras son profundamente enérgicos debido a la presteza que conlleva la acción, y a menudo son ininteligibles dando la sensación de amalgama de líneas caóticas y espontáneas; errónea percepción, ya que son acciones totalmente prediseñadas y repetidas hasta la saciedad.

Ahora bien, si para algunos las únicas representaciones estéticas que pueden denotar una condición de legitimidad plástica deben estar circunscritas en el terreno de la ofi-

18. Garí, J. La conversación mural. Fundesco, Madrid, 1995, pág. 49. 
cialidad, entonces, en ese caso, tendremos que saltar de la calle a la galería. No hay ningún libro de historia del Arte Contemporáneo que no considere al movimiento del Expresionismo Abstracto de mediados de siglo como uno de los estilos artísticos más representativos del propio siglo. Su principal característica radica en entender la realidad personal del sujeto como la única realidad posible. Fue un movimiento verdaderamente transgresor que paradójicamente cayó pronto en la aceptación y, por si fuera poco, rápidamente se enmarcó como un academicismo alternativo y actual. El hecho de que el artista entendiese su realidad individual interior como la única realidad produjo que un sector importante de los artistas pertenecientes al movimiento sintieran la necesidad de dar una primacía casi absoluta al acto mismo de pintar, ya que el motivo por representar o cualquier tipo de reflexión en torno a lo real había sido suprimido. De ahí que el artista optara por una afirmación del hecho mismo de la creación como una representación del "yo" en un tiempo y estado anímico concreto. Esta anulación de lo real por la pasión puntual de la creación era entendida como un acto puramente pulsional, o sea como un instinto biológico de creación.

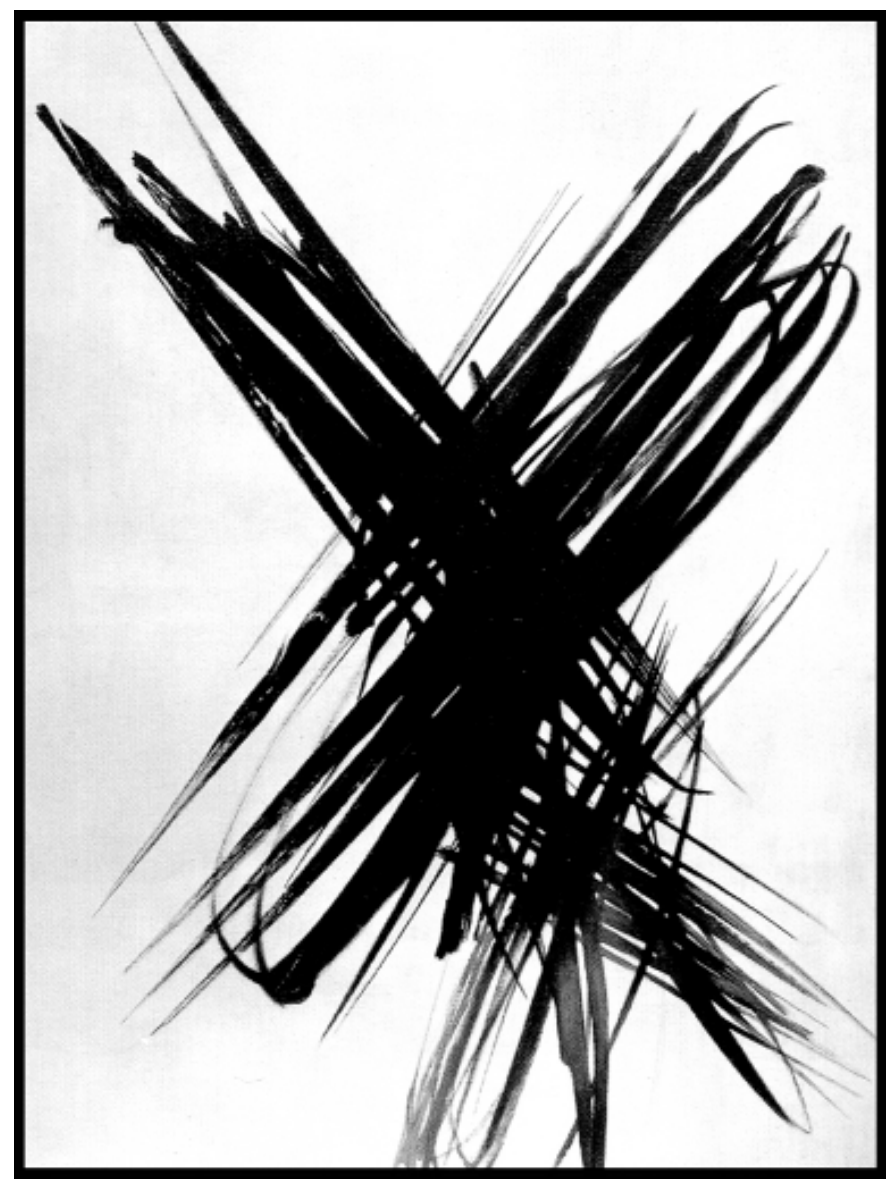

"T 1956/7" de Hans Hartung 
Jackson Pollock, uno de los artistas más representativos del movimiento,decía: "Cuando estoy en el cuadro, no me doy cuenta de lo que hago. Y es sólo después de una especie de periodo de iniciación que veo lo que he estado haciendo." 19 Artistas como Pollock, Motherwell, De Kooning y Hans Hofman, o como Franz Kline, Hans Hartung, Georges Mathieu, Mark Tobey - estos últimos atraídos además hacia la estructura del signo caligráfico estilizado- fueron fundadores de esta estética expresionista.

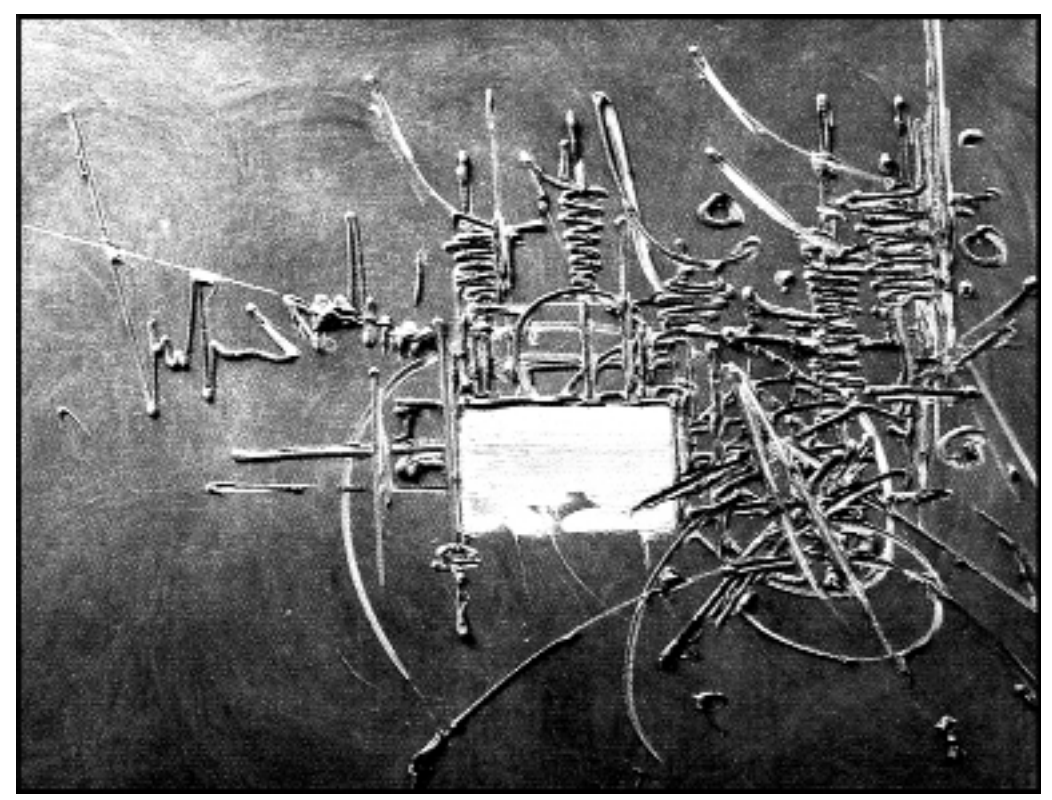

"Dâna" de Georges Mathieu

Y si analizamos sus pinturas dejando a un lado sus habilidades con los materiales, diferentes escalas, etc., y nos centramos, no sólo en su actitud frente a la obra, sino también en los propios resultados plásticos, es fácil establecer enormes vínculos de unión con la representación infantil del garabato. Dicha actitud de recreación en el acto de creación es paralela en unos y otros, incluso sus códigos de imágenes comulgan de nexos esencialmente idénticos. Pero ello no es debido a la pura casualidad: una anulación de lo real aboca hacia una destrucción de las configuraciones de patrones estéticos establecidos, lo que supone una indagación por los inicios mismos del problema estético. Y no es porque se sumergiesen en unas regresiones conscientes de evocaciones infantiles sino porque "el arte infantil contiene las formas estéticas más empleadas en todo el arte." ${ }^{20}$

"Más de una vez, los artistas profesionales sienten envidia de la espontaneidad con que los niños encaran la pintura; pues esa forma directa, esa franqueza y ese sentido intuitivo del diseño pueden muy bien ser lo que el artista está luchando por lograr."21

19. Lucie-Smith, E. Movimientos artísticos desde 1945. Ediciones Destino, Barcelona, 1991, pág. 34.

20. kellogg, R. Análisis de la expresión plástica preescolar. Cincel, Madrid,1979, pág. 54.

21. Lowenfeld, V. Desarrollo de la capacidad creadora. Kapelusz, Buenos Aires, 1972, pág. 397. 
Podría seguir añadiendo múltiples ejemplos históricos en los que una formulación plástica tan básica como el garabato se presente con todo el protagonismo estético que le corresponde, pero mi intención sólo es la de crear una vaga idea, relativa, de totalidad universal que evidencie la actitud de sistematización en los valores estéticos humanos. Evidentes, en este caso concreto del garabato, pero más evidentes, si cabe, en niveles de mayor complejidad conceptual infantil como en el del nivel preesquemático, el esquemático o el del realismo naturalista.

\section{Conclusiones}

He considerado oportuno realizar las conclusiones finales a modo de puntos, en beneficio de una mayor claridad y eficacia de entendimiento. Así pues, podemos deducir y resumir que:

- El niño aprende la educación plástica de forma interrelacional con el medio; por ello, percepción, sentimiento e intelecto están fusionados en su desarrollo; lo cual indica la posible gravedad de una mala educación estética en su formación.

- Los niños son productores de futuro. Un futuro, no muy lejano, que con toda seguridad articulará nuevas y diferentes formas de belleza que definirán una nueva conciencia estética, cuyos cimientos serán levantados a partir de a los valores que seamos capaces de transmitir. Sólo el fomento del abandono pasivo a una estéril reiteración estética, en favor de un estado intelectual que favorezca una engañosa comodidad financiada por la ausencia de la duda, es injustificable.

- Los niños tienen diferentes grados de desarrollo intelectual según sus diversas edades, y este es un proceso que se debe de tener muy en consideración a la hora de programar las propuestas de actividad creadora. El adulto no debe esperar que el niño desarrolle un aprendizaje estético superior al grado conceptual que le corresponda, pues entrometerse erróneamente en la evolución de los procesos plásticos no sólo no estimula la actividad creadora del niño sino que puede producir efectos destructivos emocionales y cognitivos en su formación.

- La estimulación estética en el niño es algo necesario pero debe ser tratada con sumo respeto. Para ello, el educador (padres y profesores) deben hacer el doble esfuerzo de, por un lado, comprometerse con el estudio de la conciencia estética histórica y actual, que le permita la formulación y enseñanza de unos criterios equilibrados, descontaminados y plurales; y, por otro lado, implicarse en el estudio de los niveles de conceptualización estética infantil para evitar posibles ataques inconscientes en el desarrollo evolutivo del niño y, al tiempo, poder comprender gozosamente dicho desarrollo y ayudar positivamente en el estímulo de las propias evoluciones. Ámbos estudios denotan estrechas afinidades de ricos diálogos dialécticos que coordinan el sentido de la definición de estética en el ser humano.

- La estética no es un subproducto cultural yermo y elitista alejado de lo cotidiano, sino que es parte de los valores que enjuician, día a día, el compendio integrador de nuestras experiencias. Entendiendo "juicio" como el equilibrio del 
intelecto en el sentimiento, deducimos que una actualización constante de la estética es un camino de libertad.

- El Arte Contemporáneo es un asombroso medio de reflexión en torno a lo humano -del mismo modo que el cine, la música, la literatura, etc., de nuestra épocaque nos sirve de tangible soporte en la difícil hora de plantearnos quiénes somos, cómo somos, hacia dónde vamos, etc.; por esta razón, el renunciar al esfuerzo que supone la aproximación a su comprensión equivale a distanciarse profundamente el hombre de sí mismo. Un abismo de lo humano en el ser humano.

"La formación del hombre, continuamente reconsiderada a lo largo de su historia y observada en todas sus particularidades, refleja las necesidades de una disposición más atenta a lo estético cuya epistemología radica en el esfuerzo interpretativo orientado a la selección de todo cuanto realmente merece ser objeto de atención y conocimiento. El viaje del hombre a través de la humanidad todavía pasa por aquí." ${ }^{\prime 2}$

\section{Bibliografía}

BELJON, J.J. 1993. Gramática del Arte. Madrid, Celeste Ediciones.

DUVIGNAUD, J. 1988. Sociología del arte. Barcelona, Ed. Península.

FERRANT, A. 1997. Todo se parece a algo. Madrid, Visor.

GARÍ, J. 1995. La conversación mural. Madrid, Fundesco.

GENNARI, M. 1994. La educación estética. Barcelona, Instrumentos Paidós.

GIEDION, S. 1981. El presente eterno: Los comienzos del Arte. Madrid, Alianza Forma.

GOMBRICH, E.H. 1997. Temas de nuestro tiempo. Madrid, Debate.

—, 1997. Gombrich esencial. Madrid, Debate.

GONZÁlEZ GARCíA, A. 1979. Escritos de Arte de Vanguardia 1900/1945. Madrid, Ed. Turner.

KELLOGG, R. 1979. Análisis de la expresión plástica preescolar. Madrid, Cincel.

LOWENFELD, V. 1972. Desarrollo de la capacidad creadora. Buenos Aires, Kapelusz.

LUCIE-SMITH, E. 1991. Movimientos artísticos desde 1945. Barcelona, Ediciones Destino.

MARCHÁN FIZ, S. 1987. La estética de la cultura moderna. Madrid. Alianza Forma.

MORRIS, D. 1980. El mono desnudo. Barcelona, Plaza y Janés.

PLATON. 1983. Las Leyes. (Libro II), Centro de estudios constitucionales, Tomo I, traducción de José Manuel Pabón, Madrid.

—, 1981. La República. (LibrollI), Centro de estudios constitucionales, Tomo II, traducción de José Manuel Pabón, Madrid.

ROBINSON, A. 1996. La historia de la escritura. Barcelona, Ed. Destino.

VIGOTSKY, L.S. 1982. La imaginación y el arte en la infancia. Madrid, Ed. Akal.

VIÑUALES GONZÁLEZ, J. 1995. Criterios de valoración del Arte Actual. Madrid, Universidad Nacional de Educación a Distancia.

22. Gennari, M. La educación estética. Instrumentos Paidós, Barcelona, 1994, pág. 307. 